\title{
A hidden Markov model for detecting multi-gene chromatin domains
}

\author{
Jessica Larson ${ }^{1 *}$, Guocheng Yuan ${ }^{1,2}$ \\ From Sixth International Society for Computational Biology (ISCB) Student Council Symposium \\ Boston, MA, USA. 9 July 2010
}

\section{Motivation}

Epigenetic regulations are important mechanisms for transcriptional control. There is evidence that neighbouring genes, although not always involved in the same pathways, are still similarly regulated via various histone modifications. Currently, most studies are limited to local epigenetic patterns, whereas methods for analysing large-scale organizations are still lacking.

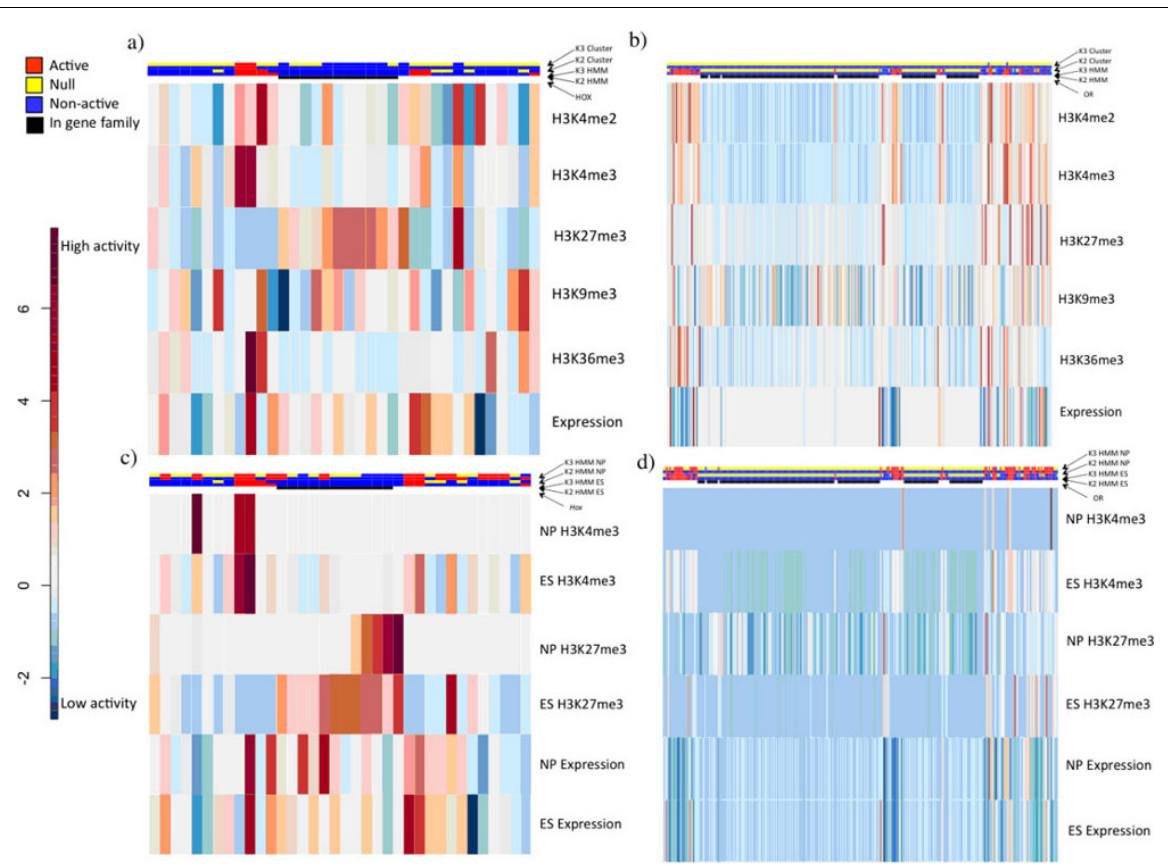

Figure 1 Heatmaps of known gene clusters. The 35 gene region on Ch6 from Npy to 2410066E13Rik as depictured as a heatmap of histone modification and gene expression for (a) the ES cell line and (c) ES and NP cell lines. The 250 gene region on Ch7 from rt2a to Insc as depictured as a heatmap of histone modification and gene expression for (b) the ES cell line and (d) ES and NP cell lines. For all figures on the left ( $a$ and c), cluster state assignment is given in the first and second tracks and HMM state assignments are in the third and fourth tracks (red for active state, blue for non-active state, yellow for null state). For figures on the right (b and d), NP HMM state assignment is given in the first and second tracks and ES HMM state assignments are in the third and fourth tracks. Whether (black) or not (white) a gene is a respective gene cluster in shown in the bottom track in all figures.

\footnotetext{
* Correspondence: jlarson@hsph.harvard.edu

'Department of Biostatistics, Harvard University, Boston, MA 02115, USA

Full list of author information is available at the end of the article
} 


\section{Methods}

We developed a computational approach to detect multi- gene domains with coherent epigenetic patterns. We applied this method to analyse a published ChIPseq dataset for five different histone modification marks (H3K4me2, H3K4me3, H3K27me3, H3K9me3, H3K36me3) in mouse embryonic stem cells. We first obtained a 5-dimenisinal score for all known genes based on average modification activity in select regions. Then, with hidden Markov models and corresponding algorithms, we were able to determine the most probable domain status of each gene. We find that a threestate hidden Markov model can best describe the data, where the states correspond to active, inactive, and null domains.

\section{Results}

This model predicts 339 significantly large multi-gene domains, including known domains such as the olfactory receptor (OR) gene clusters, but also previously uncharacterized domains (Figure 1). We also noted less histone modification variability within each of our domains when compared to randomly selected boundaries. We further validated our predictions against gene expression and Gene Ontology data and found our domains were functionally relevant.

\section{Conclusion}

Our method provides a novel approach to analyse largescale epigenetic patterns. As we continue to apply our method to other cell lines, we will provide important insight into the general structure, organization, and regulation of the mammalian genome.

\footnotetext{
Author details

1 Department of Biostatistics, Harvard University, Boston, MA 02115, USA.

${ }^{2}$ Department of Biostatistics and Computational Biology, Dana-Farber Cancer Institute, Boston, MA 02115, USA.
}

Published: 7 December 2010
Submit your next manuscript to BioMed Central and take full advantage of:

- Convenient online submission

- Thorough peer review

- No space constraints or color figure charges

- Immediate publication on acceptance

- Inclusion in PubMed, CAS, Scopus and Google Scholar

- Research which is freely available for redistribution

Submit your manuscript at www.biomedcentral.com/submit
C Biomed Central 